\title{
The added benefit of contrast-enhanced CT in evaluation of incidental FDG-avid colon lesions
}

\author{
Joseph C. Lee ${ }^{1,2}$ (D) Gemma F. Hartnett ${ }^{2,3} \cdot$ Aravind S. Ravi Kumar $^{4,5}$ (D) \\ Received: 17 January 2020 / Accepted: 3 February 2020 / Published online: 12 February 2020 \\ (C) Springer-Verlag GmbH Germany, part of Springer Nature 2020
}

\section{Dear Sir,}

We were very impressed from the outset when reading the paper published by Kirchner et al. recently [1]. It suggested a much higher incidence of detection on positron-emission tomography (PET) scan combined with computed tomography (CT) with fluorodeoxyglucose (FDG) for cancerous and precancerous lesions in the bowel and a greater degree of diagnostic accuracy than had been found in works which did not have the assistance of CT with contrast enhancement and much higher resolution [2-6]. For example, in our own study [7], scans were performed without contrast, and the CT component was acquired with a scanner with 16-slice capability. Would the authors ascribe the discrepancy purely to the difference in CT technology? Or are there other factors found to be of significance?

On further analysis, we found that the positive predictive value (PPV) was similar between the study by Kirchner [1], ours [7], and other studies [2-6] also without the assistance of contrast-enhanced CT. Agress and Cooper [2] and Kamel et al. [3] were omitted as neither the number of incidentally detected colonic lesions nor the proportion followed up was clearly documented (and hence the PPV could not be calculated).

This article is part of the Topical Collection on Letter to the Editor

Joseph C. Lee

Joseph.Lee@health.qld.gov.au

1 Department of Medical Imaging, The Prince Charles Hospital, Chermside 4032, Australia

2 Faculty of Medicine, University of Queensland, Herston 4006, Australia

3 Department of Medical Oncology, Redcliffe General Hospital, Redcliffe 4020, Australia

4 Department of Molecular Imaging and Therapeutic Nuclear Medicine, Peter MacCallum Cancer Centre, Melbourne 3000, Australia

5 Sir Peter MacCallum Department of Oncology, University of Melbourne, Parkville 3052, Australia
The PPV calculated by Gutman et al. [4], Israel et al. [5], Even-Sapir et al. [6], and our study [7] were 61\%, 46\%, $62 \%$, and $55 \%$, respectively. The PPV cited in their work [1] was $50 \%$. In that case, how much a difference did diagnostic CT really make?

\section{Compliance with ethical standards}

Conflict of interest The authors declare that they have no conflict of interest.

\section{References}

1. Kirchner J, Schaarschmidt BM, Kour F, Sawicki LM, Martin O, Bode J, et al. Incidental ${ }^{18}$ F-FDG uptake in the colon: value of contrast-enhanced CT correlation with colonoscopic findings. Eur J Nucl Med Mol Imaging. 2019. https://doi.org/10.1007/s00259-01904579-y.

2. Agress H Jr, Cooper BZ. Detection of clinically unexpected malignant and premalignant tumors with whole-body FDG PET: histopathologic comparison. Radiology. 2004;230:417-22.

3. Kamel EM, Thumshirn M, Truninger K, Schiesser M, Fried M, Padberg B, et al. Significance of incidental 18F-FDG accumulations in the gastrointestinal tract in PET/CT: correlation with endoscopic and histopathologic results. J Nucl Med. 2004;45:1804-10.

4. Gutman F, Alberini J-L, Wartski M, Vilain D, Le Stanc E, Sarandi F, et al. Incidental colonic focal lesions detected by FDG PET/CT. AJR AmJ Roentgenol. 2005;185:495-500.

5. Israel O, Yefremov N, Bar-Shalom R, Kagana O, Frenkel A, Keidar $\mathrm{Z}$, et al. PET/CT detection of unexpected gastrointestinal foci of $18 \mathrm{~F}-$ FDG uptake: incidence, localization patterns, and clinical significance. J Nucl Med. 2005;46:758-62.

6. Even-Sapir E, Lerman H, Gutman M, Lievshitz G, Zuriel L, Polliack A, et al. The presentation of malignant tumours and pre-malignant lesions incidentally found on PET-CT. Eur J Nucl Med Mol Imaging. 2006;33:541-52.

7. Lee JC, Hartnett GF, Hughes BG, Ravi Kumar AS. The segmental distribution and clinical significance of colorectal fluorodeoxyglucose uptake incidentally detected on PET-CT. Nucl Med Commun. 2009;30:333-7.

Publisher's note Springer Nature remains neutral with regard to jurisdictional claims in published maps and institutional affiliations. 